\title{
EARMYU: EXPANDING EDUCATION ACCESS AND EXCELLENCE TO HIGHLY MOBILE ONLINE LEARNERS
}

\author{
L. Dian Stoskopf \\ Director, Army Continuing Education System
}

Amy Moorash

Education Services Specialist, Army Continuing Education System

\begin{abstract}
eArmyU.com, 2004 winner of two Sloan-C awards-Excellence in Online Teaching and Programming and Effective Practice for Providing Anytime, Anywhere Online Access to Higher Education for a Highly Mobile Learner Population - is the Army's state-of-the art online education portal. Through eArmyU, Soldiers can earn a postsecondary certificate or an associates, bachelor or master degree from a home institution while taking courses from multiple education partners. Credits transfer across institutions, enabling Soldiers quickly and conveniently to progress towards their educational goals. Soldiers can research degrees, apply for admission, submit assignments, access funding for courses, register for classes with the eArmyU education partners, and assess their progress from a single integrated Web site. Delivered by the Army Continuing Education System (ACES), eArmyU supports over 57,000 mobile Solider-students by partnering with 29 regionally accredited colleges and universities to deliver online asynchronous learning anytime anywhere.
\end{abstract}

\section{KEY WORDS}

Online Learning, Virtual Student Support Services, Asynchronous Delivery, Integrated Portal, Customer Relations Management, Mobile Learners, Anytime Anywhere Learning, Government

\section{BACKGROUND}

Launched in January 2001 and touted as "the next big leap in Army education since the Montgomery GI Bill," eArmyU is a comprehensive, state-of-the-art e-learning program for active-duty enlisted Soldiers. It allows Soldiers to enroll in courses that advance them toward their chosen degree plans and apply for up to \$4,500 of annual Army Tuition Assistance (TA) benefits toward the cost of these courses through the eArmyU portal. The portal enforces Army policies regarding the use of TA while enabling Soldiers to manage enrollments, register for courses, view grades, view progress toward their degrees, and access a large network of virtual student support services from anywhere in the world.

The program has scaled from being offered as a pilot at three initial Army installations in 2001 to now being offered Army-wide at 113 Army Education Centers worldwide. Over 57,000 students have enrolled in more than 272,000 courses and these numbers continue to grow. Participating Soldiers access eArmyU from 50 countries, four U.S. territories, and all 50 states. 
eArmyU offers a wide array of certificate and degree options that support Soldier and Army needs. Currently, 147 postsecondary certificate, associate, bachelor's, and master's degree programs from 29 regionally-accredited college and universities partners are offered through eArmyU in a variety of fields, including Liberal Arts, Business Administration, Communications, Information Technology and Computers, Criminal Justice, Health Services, and Vocational Studies. For more information search the eArmyU online program listings at: https://www.earmyu.com/public/public_programs_certificates .asp?searchby=Programs.

\section{EARMYU IMPACT ON SOLDIER ACCESS AND CHOICE}

In 2000, prior to the start of eArmyU, less that five percent of the Soldier population applied their TA benefits toward distance-learning courses. Most Soldiers enrolled in classroom-based courses offered on or near their assigned Army installation. These classroom-based courses were and continue to be in high demand by Soldiers, and they form an important component of the Army Continuing Education System (ACES) options for postsecondary education. For many mobile Soldiers however, classroom-based learning was insufficient to meet their unique needs. Mobile Soldiers, frequently required to relocate, often faced educational barriers that impeded their progress toward their education goals.

Today, over 49 percent of all courses taken by Soldiers are delivered via distance learning. eArmyU represents approximately 30 percent of those course enrollments. Moreover, 27.5 percent of eArmyU students are new to postsecondary education altogether - in real numbers; this translates to approximately 15,764 Soldiers who have been attracted to higher education by the eArmyU program. Another $47 \%$ are returning to higher education through eArmyU, after a hiatus of a year or more. While much of the shift to e-learning can be attributed to technological advances, growing acceptance of online courses, and an explosion in e-learning options, several factors have influenced Soldiers to prefer eArmyU over other online options.

Value. Soldiers selecting non-eArmyU online courses must pay out-of-pocket for all services other than basic tuition. Soldiers selecting eArmyU, however, receive an Internet Service Provider, textbooks, 24/7 virtual helpdesk and technology support, online academic tutoring services, and all administrative fees bundled into their tuition rate. Eligible eArmyU Soldiers can also qualify to receive a laptop computer with all the necessary hardware and software needed to support their online learning. The eArmyU computer comes with a two-year warranty plan and the Soldier assumes full ownership of the laptop upon successful completion of 12 semester hours of eArmyU coursework in 3 years.

Choice. Soldiers earn certificates or degrees from a home institution while taking courses from any of the participating academic partners. eArmyU participating colleges and universities must be members of Servicemembers Opportunity Colleges (SOC). Participating schools offering certificate, associate or bachelor's degrees must be members of Servicemembers Opportunities Colleges Army Degrees (SOCAD) and agree to accept a common application, agree to reasonable residency requirements, twoway credit transferability among member institutions. Participating education partners also agree to provide maximum award of credit for military training and experience and college-level testing according to American Council on Education (ACE) recommended levels and the requirements of the certificate or degree program in which the Soldier is enrolled. These requirements enable Soldiers to progress quickly and conveniently toward their educational goals. Agreements such as these guarantee the Army realizes cost avoidance for tuition assistance and allows participating education partners to depend on a network of available online courses, thereby extending their online degree offerings to Soldiers. 
Low Administrative Burden for Enrollment. eArmyU eliminates the need for Soldiers to visit an Army Education center to receive tuition assistance forms. Through eArmyU, Soldiers access tuition assistance virtually and register for courses from one integrated site. Textbooks are automatically sent to the Soldier's mailing address once enrollment is confirmed. For non-eArmyU courses, Soldiers must process paperwork with their local Army Education Center, submit those forms to their school of choice (which are normally located at the education center) and register for classes. In some cases where the course is longer than 16 weeks in duration, Soldiers need to pay out of pocket and wait to receive reimbursement for tuition until after the course is completed. By streamlining the enrollment process and providing virtual access to tuition assistance and an integrated, searchable term schedule, eArmyU has decreased the administrative burden on ACES staff and personnel to process tuition assistance forms. The eArmyU portal enforces business rules for access to TA based on the Army Regulation that ensures Soldiers only register for those courses that advance them toward their degree, helping the Army recognize further cost avoidance and the Soldier to avoid financial penalty.

Tailored Student Support Services and Tools. eArmyU is augmented by an organized web of personnel and support services-Army Education Centers, Program Mentors, Helpdesk Agents, an automated Customer Relational Management (CRM) tool, Campus Points of Contact, online academic tutoring, an online writing lab, and an end-to-end virtual counseling model - that is integrated into one virtual site. These support services often exceed those provided to online students by many colleges and universities. Moreover, eArmyU offers access to 24/7 global helpdesk services through toll-free international and stateside telephone numbers and the Internet.

Technology Repair. eArmyU offers technology repair to Soldiers receiving a laptop and maintains technology repair depots in Georgia, Texas, Virginia, Korea, and Germany. These depots were established to provide continuous technology support with 24-hour repair and return service for the eArmyU laptop. Virus protection is available to Soldiers through a special arrangement with the Army.

Academic Tutoring Services. Unlimited virtual academic tutoring is provided at no cost to Soldiers, available 24/7, in subjects ranging from math to statistics to writing from Smarthinking.Com. The Online Writing Lab (OWL) is a service of Smarthinking that provides 24/7 access to writing experts who can assist students with writing on any subject.

Off-line Learning. The eArmyU Offline Learning Application (OLA) serves Soldiers with limited Internet access. Specially adapted courses with selected institutions use OLA to allow Soldiers to download course notes, assignments, bulletin board entries and other course information, work off-line, and then automatically synchronize their coursework when Internet access is restored. eArmyU offers this functionality with three participating education partners with expansion to a fourth expected in the Fall of 2005. More than 70\% of the courses taken by eArmyU Soldier-students are OLA-enabled.

\section{VIRTUAL COUNSELING}

eArmyU developed a robust proactive end-to-end virtual counseling process that greets newly enrolling students and monitors their learning progress through interventions. At the heart of that model, Program Mentors act as virtual counselors who provide a critical "human touch" often missing in the virtual learning environment. Program Mentors augment school advisors by supporting Soldiers throughout the academic journey to establish a personal mentoring relationship, to remind Soldier-students of key policies and deadlines, and to help Soldiers resolve any issues that may hinder their success in eArmyU. 
Operation Virtual Counselor Transforms Online Resources for You (ViCTORY) grew out of a need to intervene with "at risk" Soldiers as well as successful Soldiers by contacting them through a variety of personalized methods: email, telephone, and the postal system. Through a complex system of webenabled tools and strategies ViCTORY humanizes the social, community need for support in distance learning through direct, personal interactions with the Program Mentor.

\section{Operation ViCTORY Model}

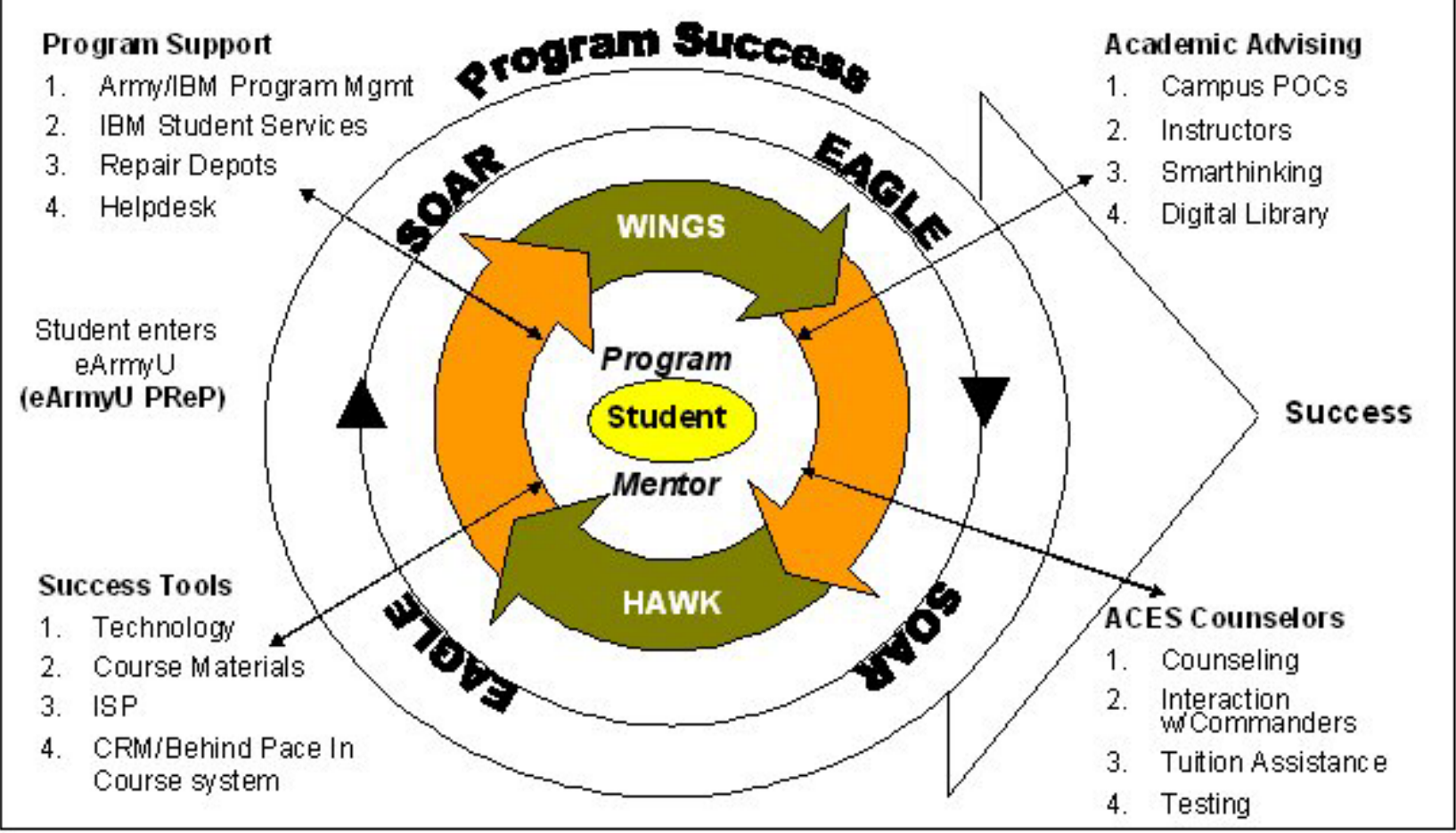

Figure 1. Operation ViCTORY Model

With Operation ViCTORY, outreach begins even before the point of enrollment. Soldiers who apply online receive an email with information on how they can talk to a Program Mentor about the benefits of eArmyU. Then, upon entering eArmyU, they receive a "Welcome to eArmyU" email that introduces the Program Mentor and reviews important information regarding program milestones.

Program Mentors proactively reach out to two major Soldier populations through Operation ViCTORY in order to help ensure Soldiers' continued success in the program. These initiatives are called "Helping Assist With Knowledge-support (HAWK)" and "With Information and Guidance to Soar (WINGS)." Through emails and follow-up telephone calls, HAWK contacts Soldiers who have not enrolled in a course within the first 30-180 days. WINGS contacts Soldiers who have registered for and/or completed their first course in the program, congratulates them on their early success, and encourages their continued progress toward completion of program milestones and degree requirements.

Early Academic Guidance for Learning Excellence (EAGLE) was developed to identify Soldiers who have fallen behind in a course and/or have fallen behind in completing program requirements. It was implemented as part of eArmyU's web-based CRM system (see section on CRM) in order to better coordinate outreach efforts across the entire student-support organization and centralize all information related to "behind-pace" Soldier cases. Program Mentors reach out to EAGLE Soldiers-identified by their instructors as being in danger of failing a course - to help them develop action plans for getting back 
on track. Instructors can monitor the actions taken by members of the student-support network and receive updates on the results of their interventions. Additionally, reminders are sent to EAGLE Soldiers regarding eArmyU's online tutoring and other portal services.

Through EAGLE, Program Mentors also reach out to Soldiers who are "behind pace" in completing program milestones. Mentors contact these Soldiers via email and phone in an effort to understand the difficulties they may be facing and remove these difficulties through coordination with the ACES Counselor, student-support network, and campus points of contact. Program Mentors follow the progress of EAGLE Soldiers until they have completed required program milestones (successful completion of 12 $\mathrm{SH}$ in 3 years.)

As Soldiers continue their progress through eArmyU, Student Online Achievement Recognized (SOAR) is the vehicle through which they are recognized for academic success, meeting program milestones, and completing degree or certificate requirements. For each achievement in these areas, SOAR Soldiers receive congratulatory emails from their Program Mentor and are featured pictorially on eArmyU's Student Recognition page.

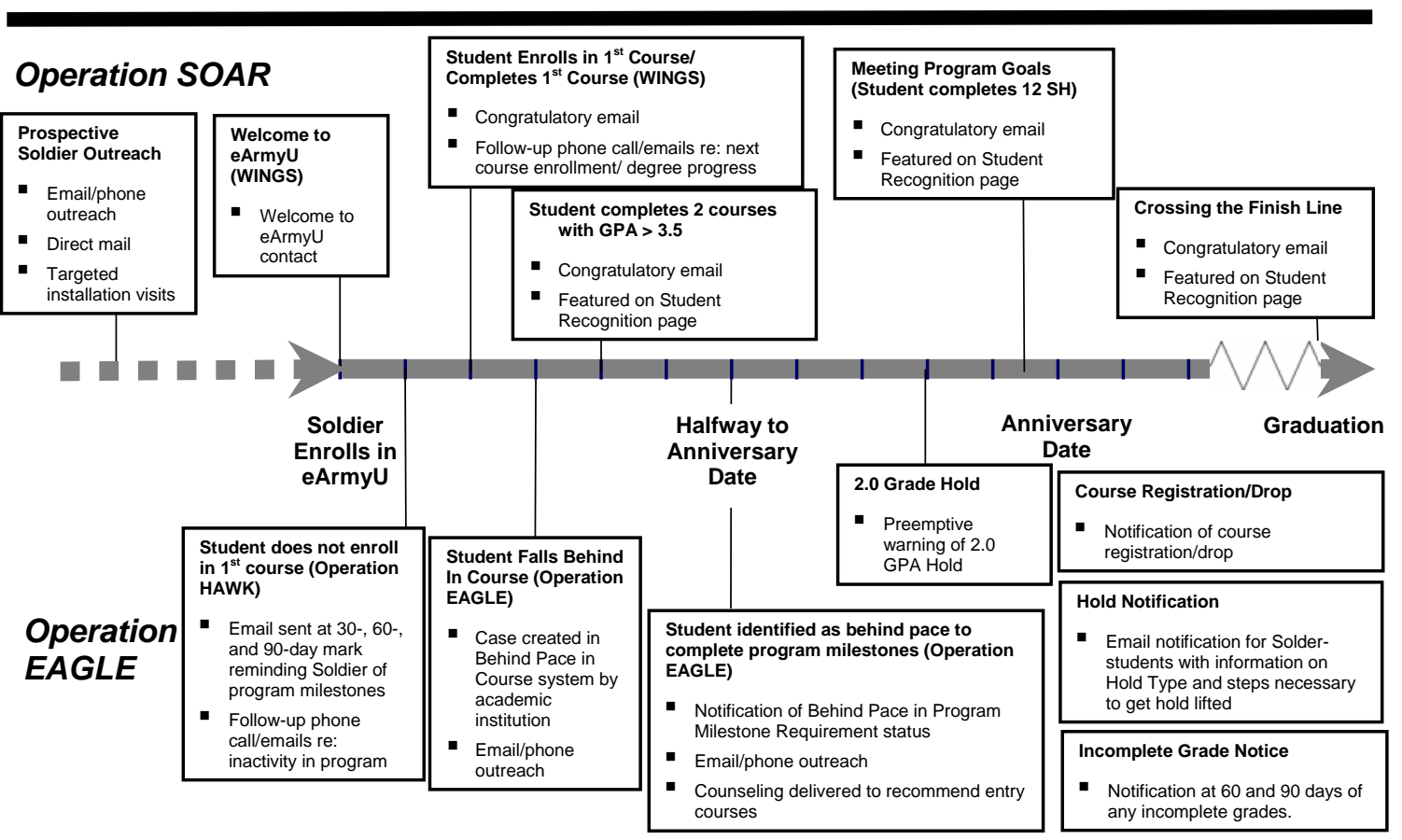

Figure 2

Every Soldier in the eArmyU program is supported by the Operation ViCTORY model. To ensure the more than 57,000 eArmyU Soldiers receive the personalized, effective service and support they need, eArmyU portal tools have been leveraged to manage, track, and operationalize the processes that comprise the Operation ViCTORY model. Criteria embedded within the communications protocol ensure that Soldiers automatically receive messages in a timely manner, allowing eArmyU Program Mentors to focus on mentoring Soldiers.

Since implementation, Operation HAWK has helped 3,214 Soldiers register for 8,336 courses, while Operation EAGLE has helped Program Mentors build relationships with more than 15,000 Soldiers. Since 
implementation, Operation EAGLE has helped 6,823 Soldiers register for 16,711 courses.

CRM Solution. Operation ViCTORY is supported by an innovative web-based customer-relation management system (CRM) specifically designed by International Business Machines Global Services, the Army's prime integrator for eArmyU. Before eArmyU implemented the CRM tool, student support services were disjointed. The burden to determine who could best resolve their questions was left to the Soldier. If the Soldier called the "wrong" support group they were told to call another number. In some cases, the student would receive conflicting information depending on who they reached. Additionally, no system was in place to provide proactive advance warning and just-in-time assistance to Soldiers at risk for falling behind in their classes or to coordinate outreach activities performed by Program Mentors.

The CRM was developed to operate through the Web to provide a central management system for a distributed student service support network. It was set up quickly with little need for expensive infrastructure and zero integration with vendor or education partner systems. Rather than placing the onus on Soldier-students to navigate this web of support resources, they simply call the helpdesk or create an online support case. The case is then routed to the specialist best equipped to help the Soldier work through his or her issue. Service-level agreements are set and enforced so that Soldiers can anticipate rapid and consistent support. Soldiers can also rate the service quality of each case closed, and monitor progress on open cases. When the case is closed, the student receives an email with the resolution and can view the full case resolution history in the eArmyU portal. This allows cases to be resolved quickly and in a coordinated way. It also allows management to use case data to track student service support against established service level agreements (SLAs) and to perform root cause analysis when a spike occurs in one type of student issue.

The timeline for the implementation of the CRM tool from concept to implementation spanned a five month period, beginning April 1, 2002 and ending on August 31, 2002. CRM solutions were researched including several Commercial Off the Shelf (COTS) packages. An objective analysis of alternative solutions confirmed that a custom developed tool was the best option given the unique student support requirements. A business case was developed for the investment and received approval from program management. Stakeholders, including education partners, the helpdesk, and program mentors were involved from the very beginning to help refine the requirements as well as agree on business rules. Because stakeholders and internal management were involved early in the process, there was buy in from all involved parties.

Enhancements were made continually to the CRM tool to leverage its technology to support Operation ViCTORY, Program Mentors, Campus Points of Contact, Helpdesk Agents, ACES Counselors, Instructors, eArmyU Vendors, and ACES Program Management under one tool. This is an innovative use of CRM because in most consortiums, each department typically has its own support systems, processes, and service level standards. With all vendors and schools tied into to one CRM solution, eArmyU Soldier-students are provided with seamless, consistent support.

To support the second part of the student success strategy, the CRM leverages a compliance tracking functionality to track student performance, flag "behind pace" students, and coordinate proactive outreach efforts. A dynamic traffic light indicator is used on the user's "Case Summary" page that shows a green light when the student is succeeding, yellow light when the student is "at risk" for falling "behind pace", and red light when the student is "behind pace" and must take immediate action. In addition, compliance data may be uploaded into the centralized reporting system via a batch FTP process that automatically uploads and updates records within the reporting system. 
The Compliance Tracker allows course instructors to log into the school's view of the eArmyU portal, search for a student in their class, and flag the student as "behind pace" in a course that is in progress. Alternatively, the school can upload an FTP file of all students at their school that are "behind pace" and the CRM will flag the students' records. The Compliance Tracker also features automatic checks. For example, if a student is not "on pace" to complete 12 semester hours in 3 years the system will flag the student. Once a student has been identified as "behind pace" whether by his or her instructor or by the CRM system, a series of outreach activities are coordinated by the tool.

Automated emails are sent to students to alert them of a potential issue and to provide the student with available resources in the student support network that can help. In addition, the traffic light indicator that the Soldier sees on their "case summary" page changes color. The student sees these indicators when he or she logs into the system. The helpdesk agents, program mentors, and other student support staff also see these indicators when they are working with a student and are trained to proactively reach out to the student if an indicator is yellow or red. Lastly, eArmyU program mentors automatically receive lists from the CRM system of students that are "behind pace" and proactively call these students to provide support. The tool has allowed eArmyU to leverage a vast support network including instructors, ACES Counselors, campus advisors, Program Mentors and the Helpdesk agents to proactively reach out to behind pace students.

Efficiency gains created by the CRM tool have enabled eArmyU to serve a growing number of Soldiers while holding support costs relatively stable. The average time to close a case has dropped from 11 business days to 1.5 business days. To date, more than 352,000 student support requests have been resolved (an average of six student-support sessions per Soldier) with high levels of student satisfaction reported in customer surveys. This kind of anytime, anywhere support has helped to humanize the distance-learning environment and minimize barriers to Soldier success. eArmyU received the 2004 EDUCAUSE award for innovation in student services in recognition of its Customer Relationship Management (CRM) tool.

\section{LESSONS LEARNED}

eArmyU is a model for use with other postsecondary programs supported by the Army Continuing Education System. Such dramatic shifts in institutional culture never come without significant lessons. Some eArmyU Soldiers, eager to receive a laptop and the conveniences of online learning, have paid high costs for their failure rates in eArmyU. ACES staff must then recoup those unsuccessful courses and apply stiff financial penalties when Soldiers do not succeed. Acting as good advisors, ACES Counselors sought to help Soldiers avoid costly mistakes that could derail their educational pursuits, but a standardized pre-enrollment assessment did not exist. To provide a more credible way of determining readiness for online learning, ACES developed a Pre-enrollment Readiness Profile (PReP) tool. Launched in Feb 2005, PReP is accessed, completed, and scored entirely online. Soldiers can stop and resume the assessment at any time. PReP assesses readiness in three broad areas: technical ability, study skills and independence learning preferences. Access to skill-building resources is provided for those Soldiers who need remediation of skills prior to enrollment. An individually-tailored readiness profile is generated for each Soldier who completes PReP which outlines how ready, willing and able the Soldier is to succeed in an online learning environment.

\section{SUMMARY/CONCLUSIONS}

Expanding access to education means more than just offering greater numbers of degree plans and course options through the Internet. It also means removing barriers to success for learners so that they can 
advance in their educational goals, integrating programs and services through a virtual doorway of support. One way this is accomplished is by maximizing support resources and minimizing the complexity associated with completing administrative processes and accessing that support. The eArmyU program and portal, CRM tool, virtual Program Mentors, ACES Counselors, Operation ViCTORY and PReP are powerful examples of how the right technology married with efficient processes and dedicated, well trained people can accomplish the goal of serving mobile learners in an online environment.

\section{ACKNOWLEDGEMENTS}

eArmyU has benefited from many stakeholders, each focused on continuously improving the program for Soldier-students. The Army Continuing Education System is providing high touch service to Soldiers with an eye to automating administrative functions and driving down operating costs. eArmyU continues to prosper as a model program that receives regular inquiries and recognition from the Department of Defense, the Higher Education Community, foreign governments, and business, training, and industry organizations. To learn more about eArmyU visit: $\underline{w w w . e A r m y U . c o m}$.

\section{ABOUT THE AUTHORS}

Ms. L. Dian Stoskopf is the Director of Education, Department of the Army, Alexandria, Va. Within the Department of the Army, the Army Continuing Education System (ACES) through its many programs and services promotes lifelong learning opportunities and sharpens the competitive edge of Army, 2010 and beyond. As Director of Education, Ms. Stoskopf oversees policy guidance for ACES at 113 Army Education Centers and 139 Multi-Use Learning Facilities worldwide. She also is responsible for and manages a budget of over $\$ 290$ million, which supports the ACES's total program and services worldwide.

Ms. Amy Moorash is an Education Services Specialist with the Army Continuing Education System Headquarters in Alexandria, VA. Her duties include functional management of the eArmyU program and other distance education initiatives. She provides eArmyU assistance to Soldiers and ACES personnel worldwide. 